\title{
Construction of Evaluation Index System of Enterprise R \& D Based on Balanced Scorecard
}

\author{
Binger Zhu \\ School of Science and Technology University, Nanjing 210000, China \\ 1143278038@qq.com
}

Keywords: Balanced scorecard, Assessment, Indicators.

\begin{abstract}
As the traditional assessment method is more concerned about the financial aspects of the indicators, little attention to non-financial aspects of performance, so the enterprise assessment is not comprehensive. This paper is based on the balanced scorecard, taking into account both financial and non-financial aspects. This paper is divided into four parts, the first is to describe the theoretical basis of the Balanced Scorecard, and then use the Balanced Scorecard theory, based on the four dimensions of the primary indicators, we built the secondary indicators, then, the enterprise $\mathrm{R} \& \mathrm{D}$ evaluation indicators system is formed. Finally, the practical application of the requirements and attention to the problem is given.
\end{abstract}

\section{Introduction}

$\mathrm{R} \& \mathrm{D}$ innovation is the enterprise's survival and sustainable development of the core competencies. With the country's emphasis on enterprise $R$ \& $D$ capabilities, the use of $R \& D$ evaluation management is more and more common. Enterprise $\mathrm{R} \& \mathrm{D}$ evaluation system is also more and more perfect, but there are still many problems. For example, more attention is focus on the financial aspects of the indicators, rather than the financial aspects of little attention. Balanced Scorecard is elaborated based on four angles, the financial, customer, internal processes, learning and growth. It takes into account the financial and non-financial aspects to build a new performance management system, which contains the strategy and the vision of the organization for the implementation of a quantitative indicator.

Therefore, the Balanced Scorecard theory has been paid more and more attention since its establishment. Many successful applications have been made abroad, and many enterprise performance management in our country has gradually introduced the Balanced Scorecard.

\section{The Theoretical Basis of Balanced Scorecard}

\subsection{The origin of the Balanced Scorecard}

The development of the Balanced Scorecard theory is divided into three stages: the embryonic period (1987-1989), the improvement period (1990-1993), the application period (1994 to present).

The late eighties of last century, many companies faced with changes in the environment on a regular basis would adjust the strategic direction to adapt to the new situation under the company's development. ADI formed a balanced scorecard initial model after the development of a strategic goal, which has taken the consideration of the company's vision, shareholders, employees, customers and suppliers and other stakeholders. Later, under the tireless efforts of Robert S. Kaplan and other scholars, the company's performance evaluation has been expanded. Since 1993, many companies have recognized the balance scorecard card and benefited from it. In the balance of scorecard card thinking slowly popularization, it has also constantly enriched.

\subsection{The contexts of balance scorecard}

The core of balanced scorecard is enterprise strategy and vision, including financial and non-financial dual perspective, combined with long-term and short-term goals, integrated with both 
internal and external groups. It can be divided into four dimensions, financial, customer, internal processes, learning and growth. The frame is shown in Fig 1.

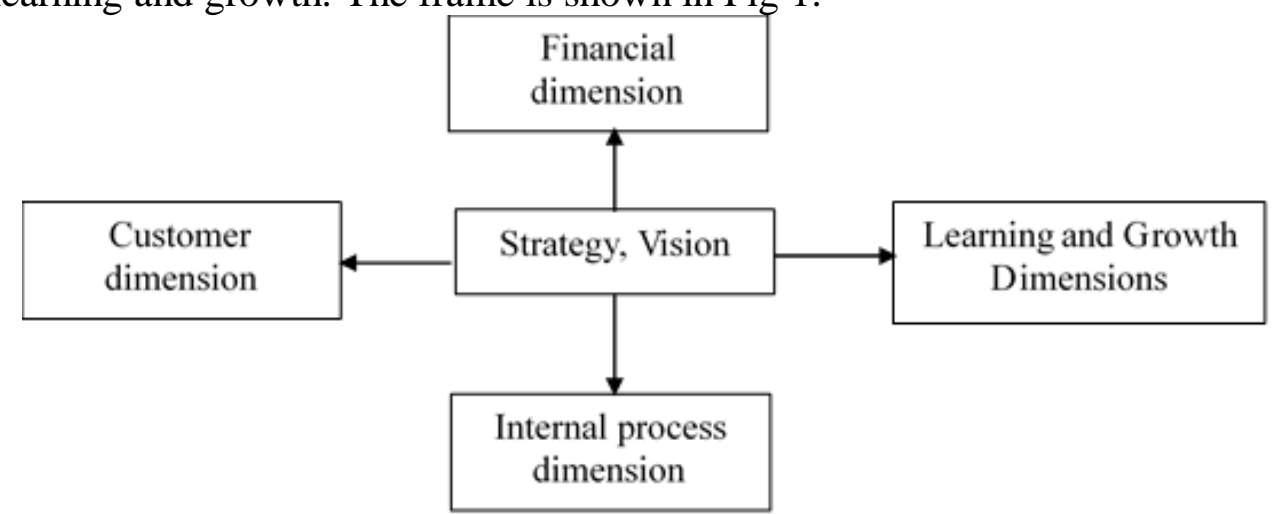

Fig. 1 The Frame of Balance Scorecard

\section{The Present Situation of $\mathbf{R} \& \mathbf{D}$ Evaluation in Chinese Enterprises}

At present, China's R \& D evaluation system gradually improved, but some unreasonable phenomenon still exists. For example, too much attention is concentrated on the results, ignoring the timely and sustained control of the middle process, resulting in beyond the grasp of the research situation at any time, leading to research is prone to bias or not suited to the market situation. In addition, the interests of $\mathrm{R} \& \mathrm{D}$ personnel and $\mathrm{R} \& \mathrm{D}$ performance is not linked, resulting in the more quick success of existing $\mathrm{R} \& \mathrm{D}$ staff. Furthermore, the evaluation of the indicators in the organization's R \& D evaluation system is based on a regular basis, however, less attention has put on the preparatory work and the middle of the assessment process. The present evaluation system is inappropriate to $\mathrm{R} \& \mathrm{D}$ project overall performance level of evaluation.

\subsection{Lack of control of the research process}

The feedback of the $\mathrm{R} \& \mathrm{D}$ process has a very important role in the success of $\mathrm{R} \& \mathrm{D}$. Through the following development process flow chart (Fig 2). Enterprise R \& D process is more complex, long cycle and full of uncertainty, so it may be successful or may fail. If you can obtain the effect of feedback information at any time in the development process, and the assessment performance, then you can always grasp the $\mathrm{R} \& \mathrm{D}$ situation in detail, and will not bring huge losses.

\subsection{Lack of assessment of the basic work of scientific research and scientific research process}

Basic scientific research work refers to the collection, analysis, research basic scientific and technological data, information, data research work. China enterprises are often not put enough attention on the basis of information collection and other scientific research generated by the hidden costs. The basic work of research is the basis of follow-up work and part of the development process.

Chinese enterprises assess their scientific research work mainly on the input of labor and financial costs, ignoring the time and other costs. In addition, it is not associated with the personal interests of the relevant staff, so the existing evaluation system cannot be very useful to motivate the staff.

Many Chinese companies use traditional performance appraisal methods, which emphasize too much on the financial indicators and ignore the assessment of the $\mathrm{R} \& \mathrm{D}$ process, resulting in an incomplete assessment. This situation makes it easily out of touch with the market, but the development process of assessment can always grasp the development of precision, dynamic and future development.

For example, Haier reformed the salary evaluation system of the R \& D staff to link with the change of customer market, then it formatted a good atmosphere of innovation. As personal interests and market links, R \& D personnel must investigate and understand the market, master the needs of customers to develop new products. 


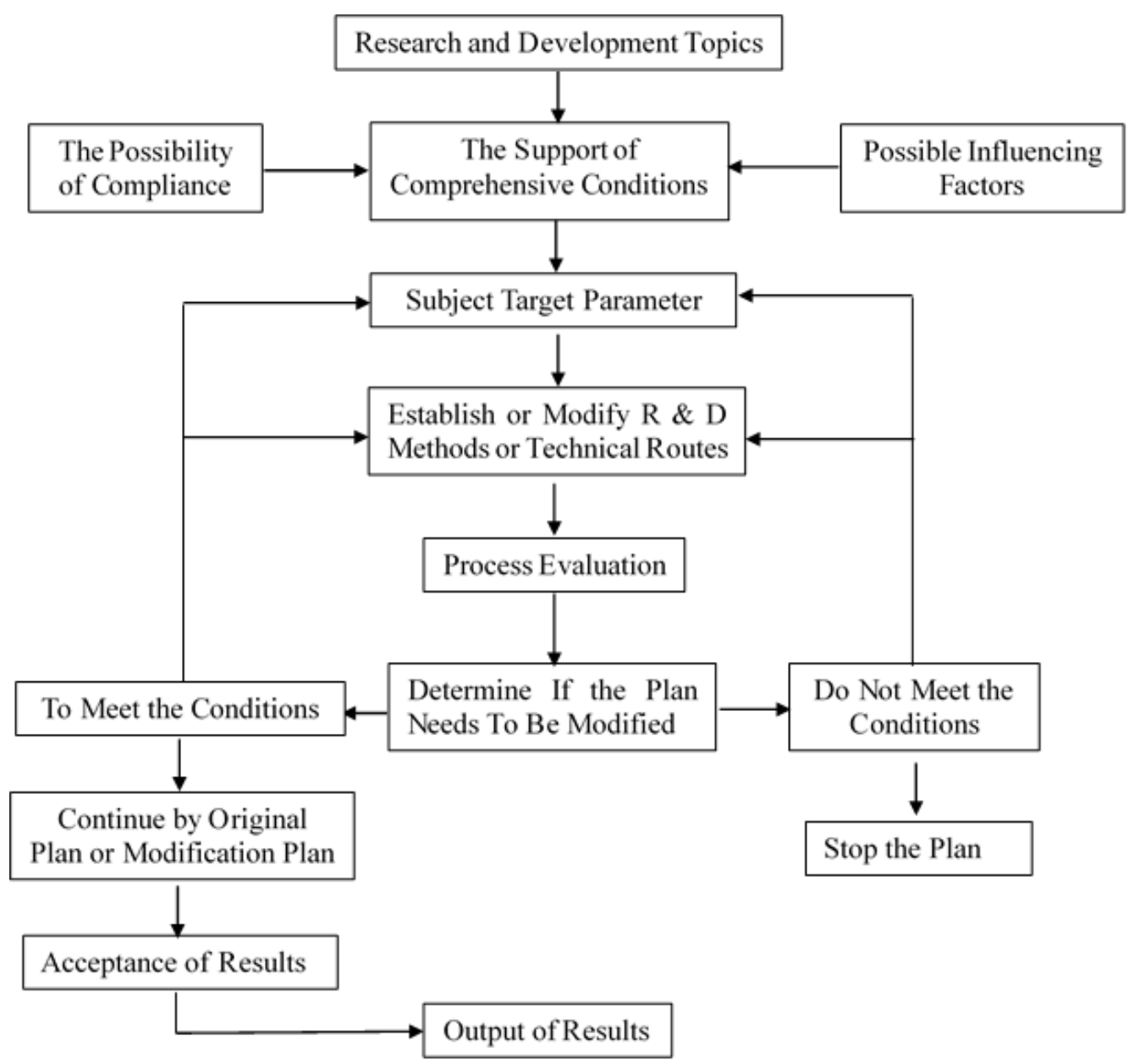

Fig 2 Development Process Flow Chart

\section{Construction of Evaluation Index System of Enterprise R \& D Based on Balanced Scorecard}

\subsection{Evaluation of design principles}

$\mathrm{R} \& \mathrm{D}$ evaluation system can set up more and more indicators, and how to design and select a suitable, effective and labor-saving indicators is the key, which need to follow the combination of principles, the consistency, comprehensiveness, measurability, qualitative and quantitative.

\subsection{Index system}

Table 1. Enterprise R \& D evaluation index system

\begin{tabular}{|c|c|c|}
\hline \multirow{14}{*}{$\begin{array}{l}\text { Enterprise R \& D evaluation index } \\
\text { system }\end{array}$} & Level 11 indicators & Secondary indicators \\
\hline & \multirow{4}{*}{ Financial dimension } & New product sales growth rate \\
\hline & & New product profit margin \\
\hline & & R \& D budget completion rate \\
\hline & & R \& D utilization \\
\hline & \multirow{3}{*}{ Customer dimension } & Customer Satisfaction Index \\
\hline & & New product market share \\
\hline & & Customer satisfaction with the service \\
\hline & \multirow{3}{*}{ Internal process dimension } & $\mathrm{R} \& \mathrm{D}$ project on time completion rate \\
\hline & & $\begin{array}{c}\text { The rate of completion of other } \\
\text { departments }\end{array}$ \\
\hline & & Process change frequency \\
\hline & \multirow{3}{*}{$\begin{array}{l}\text { Learning and growing } \\
\text { dimensions }\end{array}$} & R \& D staff satisfaction \\
\hline & & $\mathrm{R} \& \mathrm{D}$ staff retention rate \\
\hline & & $\mathrm{R} \& \mathrm{D}$ personnel training rate \\
\hline
\end{tabular}


In the construction of specific indicators, the four aspects of the Balanced Scorecard are primary indicators, and then secondary indicators are built under the primary indicators. As shown in Table 1.

\subsubsection{Financial dimension}

The indicators mainly measure the financial performance of R \& D activities, the following design of a total of four secondary indicators is given.

1. New product sales growth rate $=$ (new product sales this year - new product sales last year) $/$ new product sales last year $\times 100 \%$

2. New product profit margin $=($ new product sales revenue - new product sales cost - new product sales tax and surcharges) / new product sales revenue $\times 100 \%$

3. $\mathrm{R} \& \mathrm{D}$ budget completion rate $=\mathrm{R} \& \mathrm{D}$ expenses Actual use / R \& D budget $\times 100 \%$

4. $R \& D$ utilization $=$ number of equipment used $/$ total number of equipment

\subsubsection{Customer dimension}

That enterprises engaged in research and development is to provide customers with satisfied products and services, so as to obtain benefits for the enterprise. The following are three secondary indicators.

1. Customer Satisfaction Index $=$ Number of people who are satisfied with the random survey / Total number of random surveys

2. The share of New product market $=$ new product sales (volume) $/$ the total of market similar products sales (volume)

3. Customer satisfaction with the service (which is a qualitative indicator, the need for customers through the investigation, the interview process to obtain.

\subsubsection{Internal process dimension}

The indicators mainly evaluate $\mathrm{R} \& \mathrm{D}$ work and other parts of the work of the completion of the situation, the implementation of the development process and communication, etc., the following are a total of three secondary indicators.

1. $\mathrm{R} \& \mathrm{D}$ project on time completion rate $=$ actual completion number $/$ project plan completion number

2. The rate of completion of other departments $=$ number of requests for other departments on time / total number of requests

3. Process change frequency: This indicator refers to the number of changes in the R \& D process changes, the more the number of performance management that the worse, the indicators and for the qualitative indicators.

\subsubsection{Learning and growing dimensions}

The index refers to the development of individual R \& D personnel and team, and the extent of the loss of R \& D personnel, the following are three secondary indicators.

1. R \& D staff satisfaction: the actual staff experience and expectations compared to (through the $\mathrm{R}$ $\&$ D department staff survey to obtain the relevant data)

2. $R \& D$ staff retention rate $=$ number of $R \& D$ staff at the end of each year $/$ total number of $R \&$ $D$ personnel at the beginning of the year

3. $\mathrm{R} \& \mathrm{D}$ personnel training rate $=$ number of participants $/$ total number

\section{Suggestions on Promoting the Application of Balanced Scorecard in Enterprise R \& D Evaluation}

\subsection{Communicate with employees in a timely manner}

To implement a new performance appraisal method, we must communicate with employees in a timely manner, and always concerned about the staff response to the performance appraisal. As long as the unreasonable place, we timely adjust to ensure the effective implementation of the strategy. 


\subsection{Use appropriate methods to carry out the assessment}

We should pursuit precise performance assessment, and take into account the staff's emotions and wishes. If companies pursue too much for a rigorous approach to assessment, not only will be a waste of resources, but also will cause the loss of people. The company is a major loss.

\subsection{The system and the staff need to match}

Performance management is not an independent project, which is need for cooperation with the relevant measures. For example, the implementation of the evaluation system of their own quality is not high, then the enterprise evaluation system is useless. Therefore, we must establish a sound quality training and supervision system.

\subsection{Establish a sound feedback mechanism}

Only employees feedback on the implementation of the performance appraisal process problems timely, companies can quickly and accurately solve the problem, so companies should encourage employees to report problems in a timely manner, and format a good communication, so that organizations could run in a healthy environment.

\section{References}

[1] Speckbacher, G. , Bischof, J. , \& Pfeiffer, T. A descriptive analysis on the imple- mentation of balanced scorecards in German-speaking countries. Management Accounting Research, 14 (4), (2003), 361-388 .

[2] P.L. UmayalKarpagam, L. Suganthi. Performance measurement of organisations: a review of banlance scorecard technique [J]. Internationnal journal of business performance management, 2013(2).

[3] Kaplan, R. \& Norton, D. The Balanced Scorecard-Measures that Drive Performance, Harvard Business Review, p.(1992), 71-79

[4] Kaplan, R. S. \& Norton, D. P. The balanced scorecard - Measures that drive performance. Harvard Business Review, 70 (1), (1992),71-79.

[5] Tayler, W. B. The balanced scorecard as a strategy-evaluation tool: The ef- fects of implementation involvement and a causal-chain focus. The Accounting Review, 85 (3), (2010), 1095-1117 . 